\title{
Smart Irrigation in Agriculture
}

\author{
Lakshmiprasad C N ${ }^{1}$, Aashish $\mathrm{R}^{2}$, Syed Muzaffar J ${ }^{3}$ \\ Third Year, Department of Electrical and Electronics Engineering Kumaraguru College of Technology, \\ Coimbatore, TamilNadu, India
}

\begin{abstract}
Fresh water irrigation in the agricultural land is of raising importance. Since there is a heavy demand for the fresh water, reduced and optimal usage of resources is encouraged which can be provided by the usage of automation technologies and its apparatus like irrigation, sensors and remote operation. Emerging trends in agriculture aims at ensuring more productivity and less damage to the land which led to soil nutrient management, where the fertilizers can be met based on local requirements with go green technology. Providing latest technologies in nutrient management along with sophisticated sensor control will mentor in getting more productivity and profitability. Non destructive and efficient sensors are used to track the utility. Also the developed irrigation method removes the need for workmanship for irrigation and maintaining farm or field. The purpose of this paper is to provide more facility in agriculture field by using wireless sensor network along with linear programming and monitoring system. Paper describes an application of a wireless sensor network for low-cost wireless controlled and monitored irrigation solution.
\end{abstract}

Key words: Moisture sensor, Soil nutrient sensor, GSM Module, PIC Microcontroller, Wireless systems, Information system.

\section{Introduction}

Real time monitoring of temperature, moisture, humidity and nutrient facts of soil and atmosphere can correctly guide the agriculture and improve crop production. Precision agriculture is an agricultural system that can contribute to the sustainable agriculture concepts. If installed and programmed properly, automatic agricultural systems can even save us money and help in water conservation. Automatic agricultural systems can be programmed to discharge more precise amounts of water in the field, which promotes water conservation. At present, labor-saving and water-saving technology is a key issue in agriculture. There have not been any significant technological advancements being made in agricultural sector as compared to other sectors. Agricultural system needs to be monitored on a regular basis. The use of this project is to reduce the wastage and ensure soil quality by automating the entire agricultural system. With the help of solar energy the power need is satisfied. The added feature is the happenings in the farm are sent through a message to farm owner and the nutrient details to the server at regular intervals to improve soil quality.

\section{Features of Smart System}

The system compromises of server which are microcontroller processed with embedded sensors measuring different parameters. Here the server contains all the details of the particular locality say, nutrient content of the soil, moisture and other factors. With the help of the data, authorities can teach the farmers to plant the apt crop at the right time and get the maximum yield. Sustainable growth is established. Work of sensors is to sense the moisture, temperature and humidity.

\section{Basic Concepts}

\section{Water level Controller}

It is one of the significant operations. It might happen that the water level reaches to critical level and the motor is still running. In order to avoid such situation arrangement should be there to monitor the water level. If the subscriber wants to enquire about the water level status at a particular time, he can send a message to the centralized unit. Centralized unit checks the water level and reply the subscriber with the current status. The receiver uses a standard form of message decoding called NMEA protocol.

\section{Soil moisture sensor}

In this system, 10 HS coded pre-calibrated Soil Moisture Sensor of Decagon has been used to measure water content of soil. The 10 HS has a low power requirement and very high resolution. This gives you the ability to make as many measurements as you want (that is, hourly) over a long period of time with minimal battery usage. $10 \mathrm{HS}$ needs 12 to $15 \mathrm{~mA}$ and runs with 3 to $15 \mathrm{~V}$ DC. Output voltage of sensor is 300 to 1250 $\mathrm{mV}$ (independent from the excitation voltage). The $10 \mathrm{HS}$ measures the dielectric constant of the soil in order to find its volumetric water content (VWC) using a capacitance technique. Since the dielectric constant of water is 
much higher than that of air or soil minerals, the dielectric constant of the soil is a sensitive measure of volumetric water content.

\section{Electrochemical sensors}

Electrochemical sensors are capable of assessing spatial variability of different soil chemical properties directly or indirectly. Soil fertility is usually measured using either an ion selective electrode (glass or polymer membrane), or an ion-selective field effect transistor. This approach measures the potential voltage difference between sensing and reference parts of the system, which relates to the concentration of specific ions (i.e., $\mathrm{H}+$, $\mathrm{K}+$, NO3-) Ion-selective membrane sensors offer opportunities for on-the-go soil nutrient(s) and $\mathrm{pH}$ measurements

\section{GSM Module}

It is the communicating device which sends information to farmer or receives data from farmer for the action to be performed. It is responsible for sending data to the Agri Dept and store them in the server. The system also provides security and limited access to the third party.

\section{Limitations of Previous automated systems}

In Existing Automated Irrigation system it is not possible to operate it on decisions, it just operated only on single soil conditions like soil moisture, $\mathrm{pH}$ value, and temperature, light. It operates on only one condition at a time like if we using soil moisture sensor to control automated drip irrigation then whenever soil moisture level is get decrease then \& then only it direct the valve to change its position from OFF to ON, and if soil moisture level is go to the proper preset level at that time system is get OFF automatically. This irrigation was performed by electrically powered pumps. One of them (pump-1) carries water from Dam Lake to water tank, another one (pump-2) is used for achieving the required pressure for irrigation.

\section{Proposed Smart system}

It is somewhat similar to the existing automated irrigation system, but along with that my aim is to make my proposed system to be more intelligent, all the information about the farm is processed to the central server where they can operate the pump activity manually or automatically. Also over flooding of water over exploitation of soil is also monitored through this system via linear programming concept. The single solar powered pump is used to draw the water from lake and supply water from the tank. This reduces the consumption of electric power.

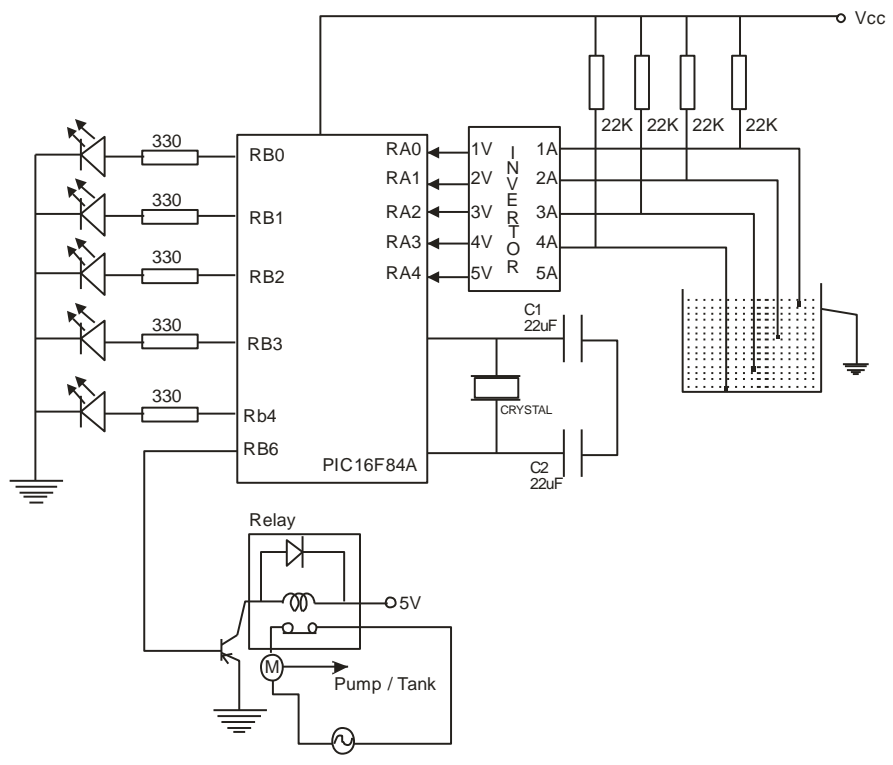

\section{Implementation details}

Initially the level of moisture, humidity and temperature are calibrated and the default value is calculated. It is programmed in such a way that if the sensor senses abnormally than the prescribed value specified actions will take place. Sensors are placed at their respective positions and the power is given to activate the sensor unit. Water level controller and pumps are aligned in such a way that they activate only when these sensor triggers out signal to microcontroller in the need of water. Nutrient kit senses the nutritional facts 
for every month and data are sent to the Server unit. GUI provides the environment for the remote monitoring utility.

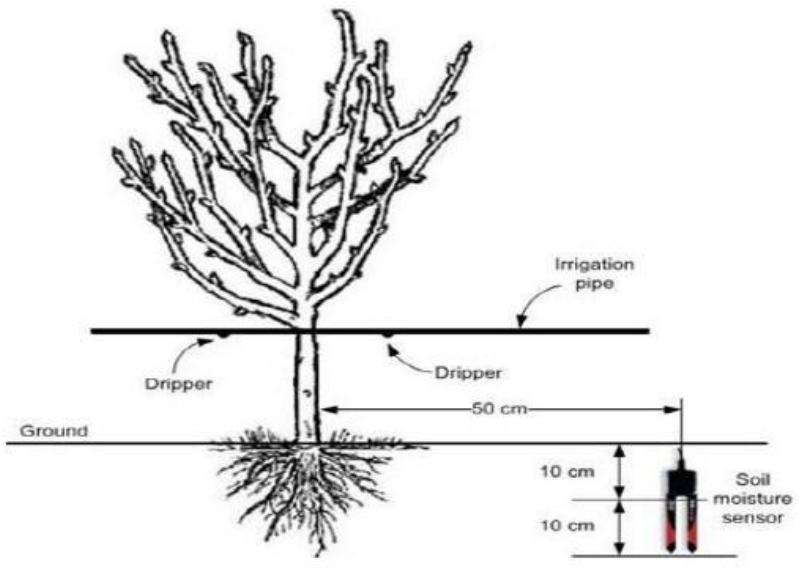

VII. Block Architecture

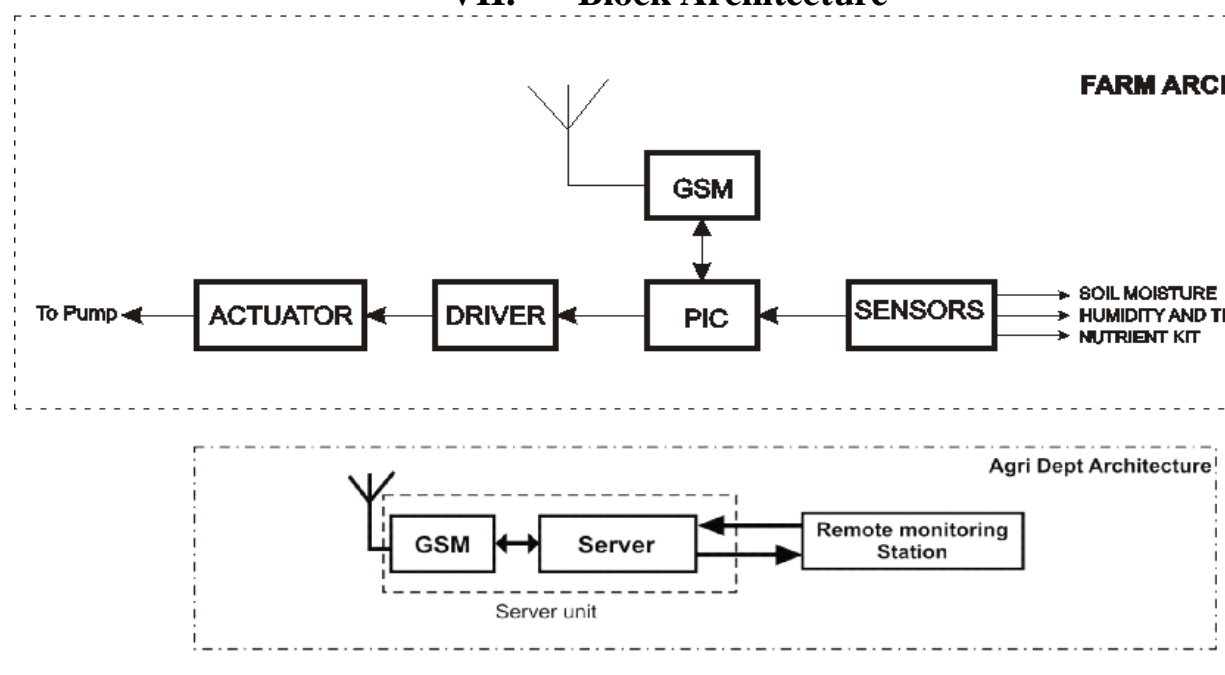

VIII. Flow chart

\section{FLOWCHART OF UNITS}

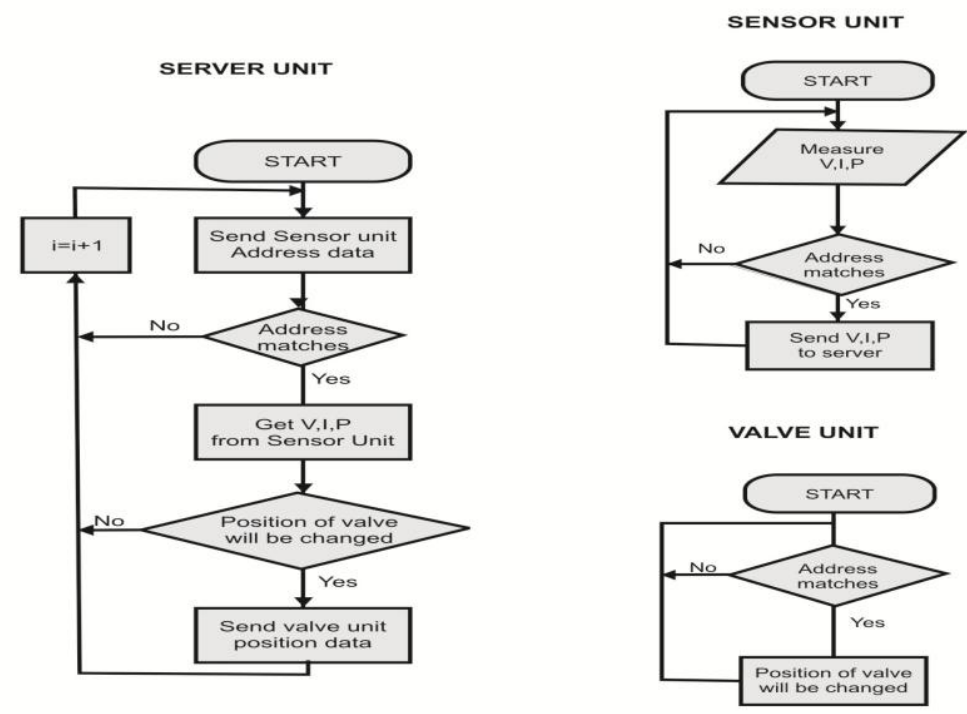




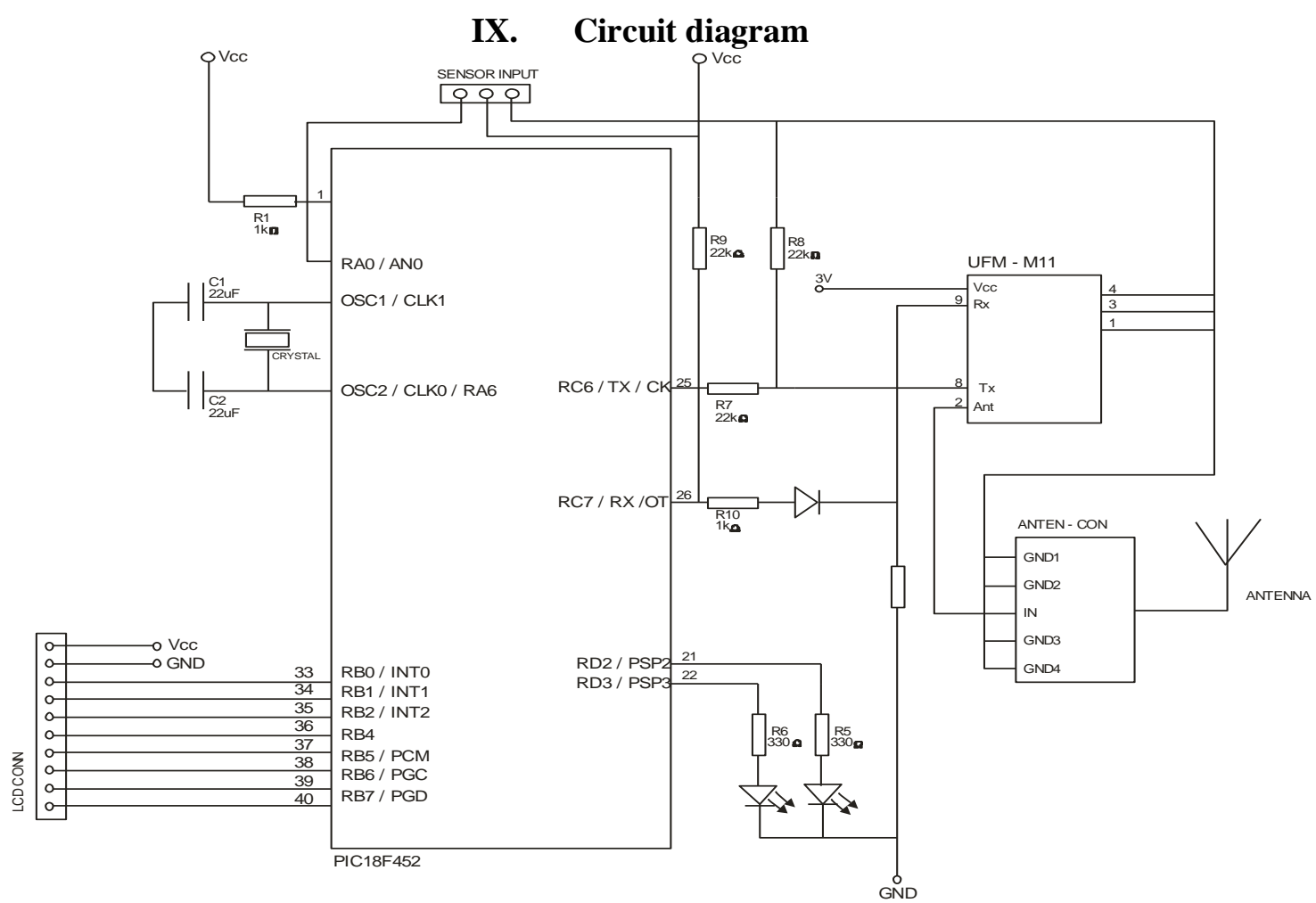

Sensors (Light, Temperature, pH Value, Humidity):

Sensor Sense the different physical parameters like light, $\mathrm{pH}$ value of soil, temperature and humidity and converts these sense data into electrical signals (either voltage or current)

\section{Signal Array:}

It is collection of various sensors basically it took input from sensor and fed that data as an input for the signal conditioning.

\section{Signal Conditioning:}

It is very essential. Generally the signal obtained from sensors are weak hence we uses signal conditioning in order to keep signal in to its original state. That means it works as like amplifier.

\section{ADC (Analog to Digital Converter):}

It Converts analog signal into digital signal and fed that digital signal to the micro controller as an in put.

\section{PIC Micro-Controller:}

It is heart of the whole system, means it controls the all activities of the system. It has memory in which control programs are saved.

\section{Sensor Unit:}

This acquires data given by the ADC, and the data sent to Server unit. Value of ADC input which comes from the sensor is stored in a 10-bit register. Different type of sensors can be added easily for future developments.

Server Unit: The server unit is a master device that is programmed to read and to evaluate sensors data, to control valves and to communicate with other units.

\section{PC (Personal Computer / Server):}

Basically for Data Acquisition as well as logging purpose we are going to use personal. The graphical visualization displays 3D Graphs generated from sensor values located across the field.

\section{Darlington Drivers:}

It is control unit which controls relays, fan, heater and water pump according to the soil conditions and provides necessary conditions to the soil means humidity, $\mathrm{pH}$ value, light, temperature. 


\section{Valve Unit:}

Valve unit has the same connection with wireless module and the same properties with sensor unit. It has an output for controlling the valve. This valve was operated digital outputs on the microcontroller by transistor.

\section{Wireless sensor network}

Wireless sensor network have a big potential for representing the inherent soil variability present in fields with more accuracy than the current systems available. WSN can operate in a wide range of environments and provide advantages in cost, size, power, flexibility and distributed intelligence, compared to wired ones. The wireless sensors are cheap enough for wide spread deployment in the form of a mesh network and also it offers robust communication through redundant propagation paths. The advantage for wireless sensor network over wired one is the feasibility of installation in places where cabling is impossible. Another obvious advantage of wireless transmission over wired one is the significant reduction in cost and simplification in wiring and harness. It has been reported that adopting wireless technology would eliminate $20-80 \%$ of the typical wiring cost in industrial installations. However, wired networks are very reliable and stable communication systems for instruments and control. Since installation of WSN is easier than wired network, sensors can be more densely deployed to provide local detailed data necessary for precision agriculture. WSN can be used for many applications such as environment monitoring, medical applications, robotic systems and home and industrial automation.

\section{Requirements}

\section{Hardware}

- GSM SIM300 module for wireless communication.

- PIC 18F452 for controlling various sensors.

- A PC for observation and running of controlling software.

- Various sensors for sensing the farm characteristics

\section{Software}

- Microsoft Visual Basic for user interface.

- SQL for database.

- $\quad$ Embedded $\mathrm{C}$ for microcontroller chip.

\section{Cost details}

\begin{tabular}{ll}
\hline Moisture Sensor & 300 INR \\
\hline Temperature and humidity sensor & 500 INR \\
PIC microcontroller & 500 INR \\
Electrochemical sensors & $400 \mathrm{INR}$ \\
GSM Module & $1500 \mathrm{INR}$ \\
Other installation charges & $1000 \mathrm{INR}$ \\
Total & $4200 \mathrm{INR}$ \\
\hline
\end{tabular}

\section{Experimental Study}

The soil moisture sensor which is used in this application has been located $20 \mathrm{~cm}$ of depth from ground and $50 \mathrm{~cm}$ far away from the tree. The irrigation system entirely has started to work and the ordinary data has been received by Server unit during irrigation at time 09:00 to 11:30. All of instantaneous the data have been recorded within $150 \mathrm{~min}$ per $3 \mathrm{~s}$, a total of 3000 data have been taken and recorded. All the analog values taken from the soil moisture sensor is sensed by a PIC, and they are converted to real volumetric water content. The analog to digital converter (ADC) is referred to an analog value sensed by a PIC microcontroller.

System application with sensor unit.

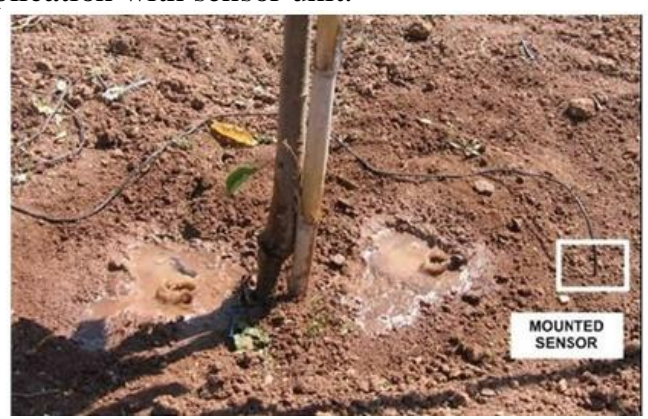

Valve unit

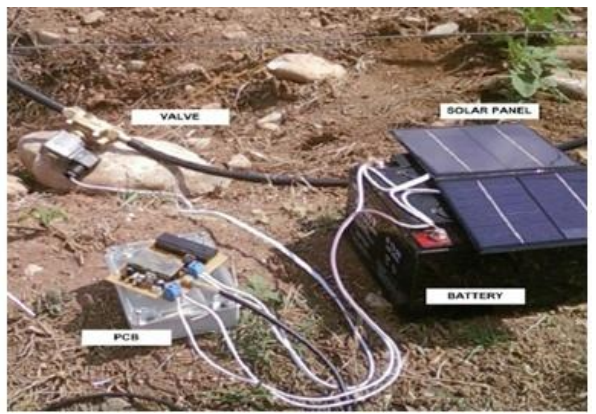

Application of the valve unit 


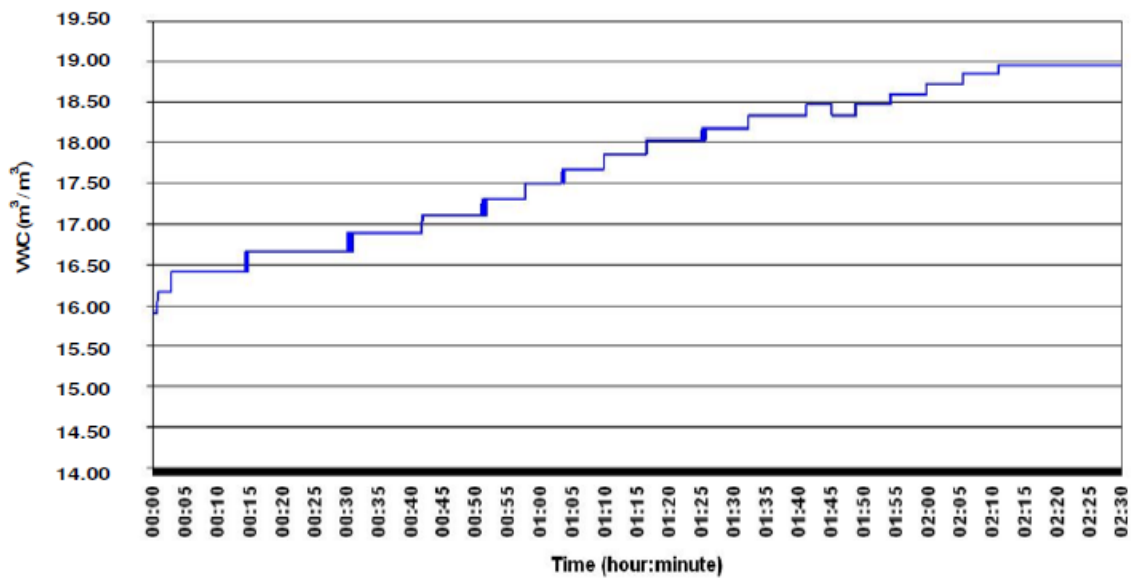

The curve of the recorded Volumetric Water Content (VWC) versus the time values.

The characteristic curve related with the V, I, P and time follows linearly. In the first hour, increasing of the curve is changed slowly; however, some ripples are being seen at passing up level.

\section{Results}

The output of Temperature Sensor is in the form of analog. The input supply voltage is 5 volts. The output will be in the form of voltage. The room temperature is 27 degree Celcius. The output will be in $\mathrm{mV}$, $290 \mathrm{mV}$. This analog is converted to digital data through ADC0808. It is directly connected to PIC microcontroller. Its calibration is simple and easy.

\begin{tabular}{|l|l|}
\hline Temp(oC) & Vout(mV) \\
\hline 27 & 270 \\
\hline 28 & 280 \\
\hline 29 & 290 \\
\hline 30 & 300 \\
\hline 31 & 310 \\
\hline 32 & 320 \\
\hline 33 & 330 \\
\hline
\end{tabular}

Table 1: Output of Temperature Sensor

The soil moisture sensor is directly connected to the microcontroller. The input supply voltage given to the sensor is 3-10 volts. The output voltage is in digital form. The digital data is directly sent to the controller. The value is displayed in the LCD.

\begin{tabular}{|l|l|}
\hline RH (\%) & Vout $(\mathbf{m V})$ \\
\hline 10 & 1325 \\
\hline 20 & 1600 \\
\hline 30 & 1860 \\
\hline 40 & 2110 \\
\hline 50 & 2360 \\
\hline 60 & 2605 \\
\hline 70 & 2860 \\
\hline 80 & 3125 \\
\hline 95 & 3555 \\
\hline
\end{tabular}

Table 2: Output of the Soil Moisture Sensor

According to the moisture level of field, the water is supplied to the field. If the moisture level of the field is low, then the water is flowed to the field. When it reaches the level, automatically microcontroller closes the valve. The water source to plants and shrubs at a carefully controlled rate by a means of flexible tubing with tiny drippers, sprayers, hoses, and bubblers attached to it. This system is economical, efficient and automated.

\section{Conclusion}

On-the-go sensors have the advantage of providing non-destructive and rapid quantification of soil variability to enable precision soil nutrient management and monitoring. The prospects of electrochemical sensors for real-time mapping of important soil chemical and physical properties to facilitate precision soil nutrient management and monitoring are promising. Using this system, one can save manpower, water to 
improve production and ultimately profit. In today's life human being is becoming so busy that he can't pay his attention to work like water supply. But plants and trees are the sources of oxygen for human being and their existence is also important from growth is also important, but it is necessary that excess supply of water should be avoided to save the water. By providing precise timing for water supply this will help to save water. Water saving is the main aim of our system and with the help of scheduling principle we have tried to achieve that, it will definitely helps the human being to save water and in such a way it will be helpful for earth.

\section{Future works}

The future scope of this project is enhanced applications with the addition of the required features. One such application is to detect the soil parameter and suggesting the proper fertilizer and its feed time. The developed system can also transfer fertilizer and the other agricultural chemicals (calcium, sodium, ammonium, zinc) to the field with adding new sensors and valves. The complete data is managed by the Agricultural Department and help in prioritizing the need and utility of the farms at right time thereby increasing the sustainability of the soil and water.

\section{References}

[1]. Mahir Dursun and Semih Ozden "A wireless application of drip irrigation automation supported by soil moisture sensors",Scientific Research and Essays Vol. 6(7), pp. 1573-1582, 4 April, 2011. Available online at http://www.academicjournals.org/SRE ISSN 1992-2248 @2011 Academic Journals.

[2]. U. Ramsing, et al. Anal. Chim. Acta, 1980, 118: 45 Adamchuk V.I.. Feasibility of on-the-go mapping of soil nitrate and potassium using ionselective electrodes. Transaction of ASAE., 2002, 02, 1183

[3]. Tahar Boutraa, Abdellah Akhkha, Abdulkhaliq Alshuaibi, Ragheid Atta; "Evaluation of the effectiveness of an automated irrigation system using wheat crops.” AGRICULTURE AND BIOLOGY JOURNAL OF NORTH AMERICA; ISSN Print: 2151-7517, ISSN Online: 2151- 7525, doi:10.5251/abjna.2011.2.1.80.88

[4]. Clemens, A.J. 1990.Feedback Control for Surface Irrigation Management in: Visions of the Future. ASAE Publication 04-90. American Society of Agricultural Engineers, St. Joseph, Michigan, pp. 255-260.

[5]. Akyildiz, I.F. \& Xudong, W. (2005). A Survey on Wireless Mesh Networks, IEEECommunication Magazine, Vol. 43, pp. S23-S30.

[6]. Bogena H R, Huisman J A, OberdÊrster C, et al. Evaluation of a low cost soil water content sensor for wireless network applications [J].Journal of Hydrology, 2007, 32-42 